\title{
Clinical decision making in ophthalmology
}

\section{J van der Meulen, J Rahi}

\section{The importance of prognosis and treatment effect}

D ecisions based on clinical examination are critical to the practice of ophthalmology. Although quite different disease processes can produce the same structural and functional outcomes, treatment decisions are often directly based on the observation of a complex of signs and symptoms. Thus, presented with a patient with sudden visual loss and/or ocular pain due to posterior uveitis, the ophthalmologist will rely on the clinical examination, in particular ophthalmoscopy, to answer three basic questions: what is wrong (diagnosis), what can we expect in the future (prognosis), and what can we do about it (effect of treatment)? But how reliable and accurate are ophthalmoscopic observations and how useful is ophthalmoscopy to support therapeutic decisions?

Stanford and co-workers, in a study published in this issue of the BJO (p 636), have tried to address some of these questions. They estimated the sensitivity and specificity of uveitis experts' interpretation of retinal photographs for the diagnosis of toxoplasma retinochoroiditis. Five experts were asked to classify the retinal photographs of 96 patients into four categories without any additional information (definitely, probably, possibly, or not toxoplasma retinochoroiditis). This is an important study as it is the first time that the diagnostic accuracy of these ophthalmoscopic findings has been investigated. A major problem the investigators had to overcome was that it is not possible to diagnose or exclude the disease with certainty, and a statistical model was therefore used to estimate the sensitivity and specificity. The sensitivity and specificity were found to vary considerably among the experts, which led the authors to conclude that a considerable number of decisions to treat patients will be wrong if they are based on a single fundal examination. There are a number of broader issues that this study raises.

Firstly, the most important aim of evaluating the signs and symptoms of patients is to identify those patients for whom the expected benefit of treatment outweighs the expected harm. For example, the best treatment for patients with toxoplasma retinochoroiditis is considered to be antibiotics in combination with systemic corticosteroids. As this treatment is associated with serious potential adverse effects, an accurate distinction between patients with and without toxoplasma retinochoroiditis is of utmost importance. On reflection however, this "stepping stone approach" (jumping from complaints to diagnosis and then from diagnosis to treatment) is in many cases rather artificial. A more pragmatic approach seems to occur in clinical practice, when the role of diagnostic information is less to identify those patients with a certain diagnosis and more to distinguish between patients who are expected to benefit from treatment and those who are not. Visual loss or pain in combination with focal retinitis and retinochoroidal scars is then taken as an indication to start treatment with antibiotics and systemic corticosteroids, as it is assumed that a patient with this complex of symptoms and signs is better off with this treatment than without it.

\section{It is not the presence or absence of a particular disease that is of most interest but the future health outcome for a patient with and without treatment}

All this may sound rather academic, but it is important to realise that such an approach focusing on clinical effectiveness (effect on patient outcome), rather than on diagnostic accuracy (for example, the sensitivity and specificity), would solve the problem that for many ophthalmological diseases an adequate reference, or gold standard for the diagnosis is not available. It is often thought that the evaluation of diagnostic tests can be divided in a number of separate steps, and that the diagnostic accuracy should be evaluated before the clinical effectiveness of a test. However, this hierarchical approach would be unhelpful when it is difficult or impossible to establish the diagnosis with certainty or when the indication for treatment is determined by the severity and nature of a known disorder rather than the presence or absence of disease itself (for example, glaucoma, diabetic retinopathy).
Secondly, the authors report the diagnostic accuracy of experts' interpretation of retinal photographs expressed in terms of sensitivity (the percentage of patients with toxoplasma choroiditis who were correctly identified) and specificity (the percentage of patients without toxoplasma choroiditis who were correctly identified) by dichotomising the four diagnostic categories (definite and probable toxoplasma retinochoroiditis versus possible or not). As a result of this, the agreement between the experts not only depends on their diagnostic abilities but also on their interpretation of statements such as probable and possible. Interestingly, the sensitivities and specificities reported for the five experts are inversely related: the sensitivity is higher if the specificity is lower. This may be partly explained by the fact that the experts indeed used different definitions or "thresholds" for the diagnostic categories. In principle, these thresholds should be based on the consequences of the diagnostic judgment for treatment. From this perspective, it is regrettable that the investigators asked the experts to classify the fundal photographs according to the presence or absence of toxoplasma retinochoroiditis and not according to the effectiveness of treatment with antibiotics and corticosteroids.

Thirdly, the investigators explore the risk of mislabelling retinal appearance by applying the estimated sensitivity and specificity of ophthalmoscopy in different populations with different prevalences of toxoplasma uveitis. Some caution is warranted when interpreting these mislabelling risks. The basic assumption underlying the estimation of the mislabelling risks is that sensitivity and specificity are constant across different settings. There is a large body of evidence, however, that indicates that sensitivity and specificity vary across different patient populations and even across subgroups within a population. In other words, the sensitivity and specificity estimated in one population of patients might not be applicable to another population. All this is again extra support for an approach of evaluating a diagnostic examination or test by focusing on clinical effectiveness in a particular clinical context rather than on diagnostic accuracy.

Lastly, the study was complicated by the lack of evidence on the prognosis of toxoplasma retinochoroiditis with and without treatment. The lack of evidence on the effectiveness of treatment is a wider problem in the evaluation of ophthalmic diagnostic tests. Many previous studies focused instead on agreement between and within different types of observers or specific test characteristics. ${ }^{1}$ Thus, an important step forward would be if studies to evaluate ophthalmic investigations always considered whether the different diagnostic results helped to identify patients who 
would benefit from the different treatment options. For the study by Stanford and co-workers, this would imply that the most important question for the experts to answer would have been whether the patient was expected to benefit from treatment with antibiotic and systemic corticosteroids. It is not the presence or absence of a particular disease that is of most interest but the future health outcome for a patient with and without treatment. Of the three basic questions that an ophthalmologist tries to answer in clinical practice for individual patients, those about the prognosis ("what can we expect?") and the potential to influence the prognosis with treatment ("what can we do about it?") ultimately take priority over the diagnostic question ("what is wrong?"). Wherever possible, future studies of diagnostic or screening tests should reflect this.

\section{REFERENCE \\ 1 Harper R, Reeves B. Compliance with methodological standards when evaluating ophthalmic diagnostic tests. Invest Ophthalmo Vis Sci 1999;40:1650-7.}

Br J Ophthalmol 2002;86:599-600

\section{Authors' affiliations}

J van der Meulen, Health Services Research Unit, London School of Hygiene and Tropical Medicine and Clinical Effectiveness Unit, Royal College of Surgeons of England, London, UK J Rahi, Centre for Paediatric Epidemiology and Biostatistics and Department of Ophthalmology, Institute of Child Health/Great Ormond Street

Hospital, London, UK

Correspondence to: Jan van der Meulen, Health Services Research Unit, London School of Hygiene and Tropical Medicine, Keppel Street, London WCIE 7HT, UK;

Jan.vanderMeulen@|shtm.ac.uk

\section{Intravitreal triamcinolone in recurrence of choroidal neovascularisation}

\section{P L Penfold}

\section{It may be useful as an adjunct to other therapies}

In

n a previous $B J O$ editorial Mori discussed the limitations of photocoagulation and photodynamic therapy, pointing to the need for pharmacological therapies that prevent the development of choroidal neovascularisation (CNV). In the May issue of the $B J O$ Ranson et al report the findings of a 14 patient uncontrolled consecutive case series in which the inclusion criteria and visual acuity data are compared with the Macular Photocoagulation Study (MPS). ${ }^{2}$ The article is the latest in a series of independent studies to employ intravitreal triamcinolone acetonide (IVTA) in the treatment of exudative retinopathy and represents a further indication for the procedure.

The visual acuity of the study group at 1 year is similar to laser photocoagulated subfoveal recurrences and better than the MPS observation group. The baseline visual acuity of patients receiving IVTA in the Ranson study was, however, marginally worse than the MPS treatment group. The authors are appropriately circumspect about the significance of their study and suggest that IVTA may be an acceptable treatment of subfoveal recurrent neovascularisation while avoiding early persistent vision loss from laser retreatment. In the discussion it is remarked that IVTA may be useful as an adjunct to other therapies, including photodynamic therapy.

The study provides an additional impression of the potential side effects of intravitreal triamcinolone administration—for example, three of 14 eyes required topical suppressants for mild elevation of intraocular pressure, consistent with clinical expectation. Studies involving IVTA, published to date, have reported no significant incidence of endophthalmitis, vitreous haemorrhage, retinal detachment or visual field loss, although, an increased incidence of lens opacities has been described ${ }^{4-6}$ In the article by Ranson et al, in contrast with previous studies, no clinically significant effect on cataract progression was evident despite the use of an identical regimen and dose $(4 \mathrm{mg}$ Kenalog). It is tempting to speculate why this may be so. One possibility is that recurrent neovascularisation is associated with modulation of cytokine profiles within the vitreous which may influence cataractogenesis. Alternatively, in a setting where extensive neovascularisation has occurred, increased expression of glucocorticoid receptors by choroidal new vessels may reduce the bioavailability of the steroid to receptors in the anterior segment and lens.

A number of clinical pilot studies have previously examined the therapeutic potential of IVTA for the treatment of exudative age related macular degeneration (AMD). ${ }^{4-6}$ IVTA has also been reported to be potentially efficacious for the treatment of diabetic retinopathy, cystoid macular oedema (CMO) associated with uveitis, ${ }^{89}$ and birdshot retinochoroidopathy. ${ }^{10}$ Martidis et $a l^{10}$ observe that the intravitreal route of administration alleviates the pharmacological issues of penetration and bioavailability. In a randomised trial comprising 27 patients with exudative macular degeneration, including occult and classic lesions, Danis et $a l^{6}$ reported short term improvement in visual acuity using IVTA. The study additionally reported favourable fundus findings, which reflect the statement "angiographic images are similar to baseline" in the present study (Fig 1B).

\section{The mode of action of triamcinolone on human choroidal endothelial cells remains to be completely defined}

The rationale for the use of glucocorticoids for the treatment of exudative macular degeneration has been derived from observations of both animal models $^{11-14}$ and pathological specimens. ${ }^{15}$ Evidence relating leucocytes and cytokines to the aetiology of choroidal new vessels and the role of retinal microglia in AMD has been reviewed previously. ${ }^{16}$ In vitro studies indicate that triamcinolone has the capacity to modulate epithelial cell resistance and ICAM-1 expression. The findings are consistent with clinical observations indicating that reduction of the permeability of the outer blood-retinal barrier, resorption of exudation, and downregulation of inflammatory stimuli are the principal effects of intravitreal triamcinolone in vivo. ${ }^{15}$ While CNV is most commonly found in AMD, its occurrence in younger patients with posterior uveitis and other inflammatory conditions suggests that chorioretinal inflammation may be a principal aetiological factor in the development of $\mathrm{CNV}^{17}{ }^{17}$ Glucocorticoids are known to display differential capacities to mediate antiangiogenic, anti-inflammatory and permeability effects, although the mode of action of triamcinolone on human choroidal endothelial cells remains to be completely defined.

Br J Ophthalmol 2002;86:600-601 


\section{Author's affiliations}

P L Penfold, Department of Ophthalmology, University of Sydney, Box 4337, Sydney 2001,

Australia; ppenfold@eye.usyd.edu.au

\section{REFERENCES}

1 Mori F. The role of choroidal haemodynamic abnormalities in the pathogenesis of age related macular degeneration. $\mathrm{Br} J$ Ophthalmol 2001:85:1399-400.

2 Ranson NT, Danis RP, Ciulla TA, et al. Intravitreal triamcinolone in subfoveal recurrence of choroidal neovascularisation after laser treatment in macular degeneration. Br J Ophthalmol 2002:86:527-9.

3 Wingate RJ, Beaumont PE. Intravitreal triamcinolone and elevated intraocular pressure Aust NZ J Ophthalmol 1999;27:431-2.

4 Penfold PL, Gyory J, Hunyor A, et al. Exudative macular degeneration and triamcinolone. A pilot study. Aust NZ J Ophthalmol 1995;23:293-8.

5 Challa JK, Gillies MC, Penfold PL, et al. Exudative macular degeneration and triamcinolone. 18 month follow up. Aust NZJ Ophthalmol 1998;26:277-81
6 Danis RP, Ciulla, TA, Pratt LM, et al. Intravitreal triamcinolone acetonide in exudative age-related macular degeneration Retina 2000;20:244-50

7 Jonas JB, Hayler JK, Sofker A, et al. Intravitreal injection of crystalline cortisone as adjunctive treatment of proliferative diabetic retinopathy. Am J Ophthalmol 2001;131:468-71.

8 Young S, Larkin G, Branley $M$, et al. Safety and efficacy of intravitreal triamcinolone for cystoid macular oedema in uveitis. Clin Exp Cystoid macular oedema in

9 Antcliff RJ, Spalton DJ, Stanford MR, et al. Intravitreal triamcinolone for uveitic cystoid macular edema: an optical coherence tomography study. Ophthalmology 2001;108:765-72.

10 Martidis A, Duker JS, Puliafito CA. Intravitreal triamcinolone for refractory cystoid macular edema secondary to birdshot retinochoroidopathy. Arch Ophthalmol 2001;119:1380-3.

11 Chandler DB, Rozakis G, de Juan EJ, et al. The effect of triamcinolone acetonide on a refined experimental model of proliferative vitreoretinopathy. Am J Ophthalmol 1985:99:686-90.

12 Antoszyk AN, Gottlieb JL, Machemer R, et al. The effects of intravitreal triamcinolone acetonide on experimental pre-retinal neovascularization. Graefes Arch Clin Exp Ophthalmol 1993;231:34-40

13 Ishibashi T, Koichiro M, Sorgente $N$, et al. Effects of intravitreal administration of steroids on experimental subretinal neovascularization in the subhuman primate. Arch Ophthalmol 1985;103:708-11.

14 Ciulla TA Criswell MH, Danis RP, et al. Intravitreal triamcinolone acetonide inhibits choroidal neovascularization in a laser-treated rat model. Arch Ophthalmol 2001;119:399-404.

15 Penfold PL, Wong JG, Gyory J, et al. Effects of triamcinolone acetonide on micoglial morphology and quantitative expression of MHC-II in exudative AMD. Clin Exp Ophthalmol 2001;29:188-92.

16 Penfold PL, Wen L, Madigan MC, et al. Triamcinolone acetonide modulates permeability and intercellular adhesion molecule-1 (ICAM-1) expression of the ECV304 cell line: implications for macular degeneration. Clin Exp Immunol 2000;1 121:458-65.

17 Penfold PL, Madigan MC, Gillies MC, et al. Immunological and aetiological aspects of macular degeneration. Prog Ret Eye Res $2001 ; 20: 385-414$

\section{Clinical Evidence-Call for contributors}

Clinical Evidence is a regularly updated evidence based journal available world wide both as a paper version and on the internet. Clinical Evidence urgently needs to recruit a number of new contributors. Contributors are health care professionals or epidemiologists with experience in evidence based medicine and the ability to write in a concise and structured way.

We are presently interested in finding contributors with an interest in the following clinical areas:

$\begin{array}{ll}\text { Acute bronchitis } & \text { Hepatitis B } \\ \text { Acute sinusitis } & \text { Hepatitis C } \\ \text { Cataract } & \text { HIV } \\ \text { Genital warts } & \end{array}$

Being a contributor involves:

- Appraising the results of literature searches (performed by our Information Specialists) to identify high quality evidence for inclusion in the journal.

- Writing to a highly structured template (about 1500-3000 words), using evidence from selected studies, within 6-8 weeks of receiving the literature search results.

- Working with Clinical Evidence Editors to ensure that the text meets rigorous epidemiological and style standards.

- Updating the text every eight months to incorporate new evidence.

- Expanding the topic to include new questions once every 12-18 months.

If you would like to become a contributor for Clinical Evidence or require more information about what this involves please send your contact details and a copy of your CV, clearly stating the clinical area you are interested in, to Polly Brown (pbrown@bmigroup.com). 